\title{
Pediatrik Olguda EDTA’ya Bağlı Psödotrombositopeni
}

\author{
EDTA-Dependent Pseudothrombocytopenia in a Pediatric Case
}

Muharrem Çiçek, Merve Aktaș, Neval Topal

Kanuni Sultan Süleyman Eğitim ve Araștırma Hastanesi, Çocuk Sağlığı ve Hastalıkları Anabilim Dalı, İstanbul, Türkiye

Correspondence:

Muharrem ÇİÇEK,

Kanuni Sultan Süleyman Eğitim ve Araştırma Hastanesi, Çocuk Sağlı̆̆ı ve Hastalıkları Anabilim Dalı,

İstanbul, Türkiye

e-mail: dr_mcicek@hotmail.com

\section{Özet}

Etilen-diamine-tetra-asetik asit (EDTA) laboratuvarda antikoagülan olarak yaygın olarak kullanılmaktadır. EDTA'nın neden olduğu psödotrombositopeni, çocuklarda nadir görülen bir fenomendir. Bu vakaların tespiti, yanlış tedavi ve uygulamaların önlenmesi açısından son derece önemlidir. Bu pediatrik olgu sunumunun amacı, EDTA'ya bağlı psödotrombositopeniye dikkat çekmektir.

Anahtar Kelimeler: EDTA, psödotrombositopeni, pediatri

\section{Abstract}

Ethylene-diamine-tetra-acetic acid (EDTA) is widely used as anticoagulant in laboratory. EDTA-dependent pseudothrombocytopenia is a rare phenomenon in children. The detection of these cases is extremely important for prevention of the wrong treatments and practices. The aim of this pediatric case report was to draw attention to EDTA-dependent pseudotyhrombocytopenia.

Keywords: EDTA, pseudotrombocytopenia, pediatrics 


\section{Giriş}

Trombosit üretim bozukluğu yada trombosit yıkımına bağlı olarak oluşabilen gerçek trombositopeniye ek olarak etilen-diaminetetra-asetik asit (EDTA) veya sodyum sitrat içeren tüplerde antitrombosit antikorlar nedeniyle gelişen trombosit agregasyonuna bağlı olarak otomatize kan sayım cihazlarında yanlışlıkla düşük sayılması nedeniyle kanama riskini artırmayan ve trombosit transfüzyonuna gerek olmayan in vitro psödotrombositopeni ile nadiren de olsa karş1laş1labilmektedir $(1,2)$. Transfüzyonlar ve splenektomiye kadar giden gereksiz girişimler olabileceğinden kanama, peteşi ve ekimozlar1 olmayan, klinik ile uyumsuz trombositopeni vakalarında ayırıcı tanıda psödotrombositopeni de düşünülmelidir $(1,3)$. $\mathrm{Bu}$ pediatrik olgu sunumu, düşük trombosit sayımının olası nedenlerinden biri olan EDTA'ya bağl1 psödotrombositopeniye (EDTA-PT) dikkat çekilmesi amaciyla sunuldu.

\section{Olgu Sunumu}

İki hafta önce baş ağrısı sebebi ile gittiği dış merkez acil servisinde yapilan tetkiklerinde trombosit düşüklüğü $(3000 / \mu \mathrm{L})$ saptanmas1 üzerine kontrol önerilen 16 yaşında kız hasta, kurumumuz çocuk acil servisine hemogram kontrolü için başvurdu. Farkl1 merkezlerde farklı zamanlarda çalışılan üç hemogram testinde (EDTA içerikli) trombosit sayısının $10000 / \mu \mathrm{L}$ altında saptandığ 1 geçmiş tetkik raporlarında görüldü. Genel durumu iyi olan aktif şikayeti olmayan olguda, sistem muayeneleri doğal olup, aktif kanama, ekimoz, peteşi, purpura izlenmedi. Düşük trombosit sayısına bağlı olarak gastrointestinal, üriner ve beyin kanaması gibi olası klinik tablolarla karşılaşma ihtimaline karş1 olgumuzda anksiyete ve irritabilite mevcuttu. Ailesinde kanama bozukluğu olmayan hastanın özgeçmişinde epistaksis, menoraji, gastrointestinal, üriner kanama ve geçirilmiş operasyon öyküsü yoktu.

EDTA'lı tüpe alınan hemogram tetkiklerinde trombosit say1s1 $2000 / \mu \mathrm{L}$, lökosit $6120 / \mu \mathrm{L}$, hemoglobin $12,8 \mathrm{mg} / \mathrm{dL}$, hematokrit $\% 36.5$ olarak sonuçlandi. Biyokimya ve koagülasyon parametreleri normal aralıklarda saptand1. Laboratuvarca muhtemelen pihtilı notu düşülen ve trombosit değeri düşük olan hastanın hemogram testi (EDTA içerikli) tekrarlandı ve kontrolünde trombosit değeri $7000 / \mu \mathrm{L}$ olarak saptand. Trombosit düzeyi, klinik durumuyla uyumlu olmadığ 1 için parmak ucu kandan periferik yayma yapıldi; trombositler yeterli olup, her alanda 15-20'li kümeli ve normal boyutta trombositler görüldü. EDTA-PT öntanısıyla hastadan sitrat ve lityum heparin içerikli iki ayrı tüpte çalışlan hemogram testinde, trombosit değerleri sirasiyla $241000 / \mu \mathrm{L}$ ve $112000 / \mu \mathrm{L}$ saptandi. Hastaya mevcut bulgular 1şığında EDTA-PT tanısı konuldu ve önerilerle taburcu edildi.

\section{Tartışma}

Psödotrombositopeni, kandaki antitrombosit antikorlar nedeniyle gelişen in vitro trombosit kümelenmesine bağlı olarak otomatize sistemlerde sayıldığında yalancı düşük trombosit sayılarıyla sonuçlanan bir laboratuvar bulgusudur (3). Kanama riskini artırmadığ 1 gibi trombosit transfüzyonu yapilmasina gerek olmayan psödotrombositopeni olgularında transfüzyonlar ve splenektomiye kadar giden gereksiz girişimler olabilmektedir $(1,2)$. Trombosit satellitozu, trombosit soğuk aglütininlerinin veya dev trombositlerin varlığı, eritrosit sayısının 6.5 milyon/mm3'ün üzerinde olması, büyük trombositler, küçük piht1lar, uygun olmayan kan numunesi alım tekniği ve hemogram tüplerinde bulunan EDTA'ya bağlı kümelenme gibi sebeplere bağlı olarak psödotrombositopeni görülebilmektedir (3, 4). EDTA, laboratuvarlarda tam kan sayımı için yaygın olarak kullanılan bir kalsiyum şelatör antikoagülandır. İlk olarak Gowland ve ark. tarafindan $1969^{\prime}$ da tanımlanan EDTA-PT, çoğunlukla $0^{\circ} \mathrm{C}$ ile $4^{\circ} \mathrm{C}$ arasında optimum şekilde reaksiyona giren, sitoadezif reseptörleri gpIIb-IIIa'yı tanıyan, aktivasyon antijenlerinin ekspresyonunu uyaran, tirozin kinaz aktivasyonunu tetikleyen, trombosit aglütinasyonu ve kümelenmeyi tetikleyen EDTA'ya bağlı antiplatelet antikorlarının 
varlığından kaynaklanan ve sonunda yalancı bir şekilde azalmış trombosit sayımına yol açmasıyla, genel popülasyonda yaklaşık $\% 0,1$ olarak görülen nadir bir fenomendir (4-6). Nadir olarak karşılaşılması nedeniyle, tanımlanması ve önlenmesi, yanlış tanı veya gereksiz tedaviden kaçınmak çok önemlidir. Olgumuz herhangi bir klinik bulgu ve semptom göstermemesine rağmen farklı günlerde, üç farklı merkezde EDTA'lı tüpte çalışılan üç hemogram testinde trombosit sayısının $10000 / \mu \mathrm{L}$ altında saptanmış ve tekrarlayan kontrollere çağrilmıştır. Son 2 haftada test verdiği sağlık kuruluşlarındaki sağlık personellerinin düşük trombosit sayısına bağlı olarak gastrointestinal, üriner ve beyin kanaması gibi olası klinik tablolarla karşılaşma ihtimaline karşı uyarıları doğrultusunda olgumuzda anksiyete ve irritabiliteye sebep olduğu görülmüştür. Başvurulan farklı merkezlerde, gerçek ve yalanc1 trombositopeni ayrımı yapılamadığ 1 için olgumuzda zaman, iş gücü, ekonomik kayılara ve en önemlisi psikolojik rahat $\neg$ sizlığa neden olmuştur.

EDTA-PT'den şüphelenildiği durumlarda, sodyum sitrat veya heparin gibi diğer antikoagülanlarla tam kan sayımının tekrarı ve ayrıca trombosit sayılarının ve kümelerinin varlığının değerlendirilmesi için periferik kan yaymasının mikroskobik incelenmesi ile doğrulanması gerekmektedir (7). Rutin olarak her merkezde kan numunelerinin mikroskopik incelemesinin yapılmadığı için EDTA-PT

\section{KAYNAKLAR}

1. Börekçi E, Özdemir ZT, Şahin S, Yıldırım T. Yalanc1 trombositopeni saptanan bir olgu. Bozok Tip Dergisi. 2016;6:64-7.

2. Büyükateş $\mathrm{M}, \mathrm{E} \mathrm{C}$, . Koroner arter bypass greft cerrahisi sonrası oluşan psödotrombositopeni ve literatürün gözden geçirilmesi. Genel Tip Dergisi. 2014;24:17-9.

3. Canpolat G, Koçak-Tufan Z, Bulut C, Alioğlu B, Kınıklı S, Demiröz AP. EDTA'ya bağlı psödotrombositopeni sonucu gereksiz transfüzyon yapılan bir kırım-kongo kanamalı ateşi olgusu. Klimik Dergisi. 2011;24:184-6.

4. Lin J, Luo Y, Yao S, Yan M, Li J, Ouyang W, et al. Discovery and correction of spurious low platelet counts due to EDTA-dependent saptanamamakta ve gerçek trombositopeni ile kolayca karışmaktadır (1). Olgumuza farklı merkezlerde sadece EDTA içerikli üç hemogram testi yapılmış olup, deneyimli personel ve ekipman gereksinimi olan periferik kan yayması incelemesi yapılmadığı gibi psödotrombositopeni ayırıcı tanısı için çoğu laboratuvarda kolaylıkla yapilabilecek olan diğer antikoagülanlarla tam kan sayımı testleri çalışılmamıştır. Olgumuzun kurumumuza başvurusunda yapılan rutin kan tetkiklerinde EDTA içerikli hemogram testinde trombosit değerleri düşük saptanmıştır. Olgumuzun trombosit düzeyi, klinik durumuyla uyumlu olmadığ 1 için sitrat ve lityum heparin içerikli iki ayrı tüpte trombosit değerleri sırasıyla $241000 / \mu \mathrm{L}$ ve $112000 / \mu \mathrm{L}$ saptanip, parmak ucu kandan periferik yaymas1 ile EDTA-PT tanıs1 konuldu. Sitrat, oksalat, heparin ve asit-sit $\neg$ rat dekstroz gibi diğer antikoagulanlarla da psödotrombositopeni meydana gelişebileceği literaturde bildirilmiş olup (1), olgumuzda sitrat ve lityum heparin içerikli iki ayrı tüpteki trombosit değerlerindeki farkı açıklamaktadır. Periferik yayma değerlendirmesine göre olgumuzda, sitrat içerikli hemogram sonucunun daha gerçekçi olduğunu düşündük.

\section{Sonuç}

Klinik durumuyla uyumsuz olarak trombosit düzeyi düşük saptanan olgularda psödotrombositopeniden şüphelenilmeli, gereksiz tedavi, zaman ve maliyet kayıplarına karşı dikkatli olunmalıdır. 